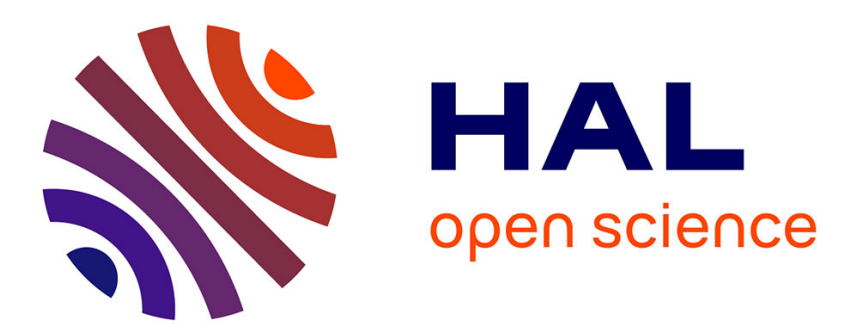

\title{
Crystal structure and physical properties of the new ternary compounds Nd3Pt23Si11 and Pr3Pt23Si11
}

Christine Opagiste, Rose-Marie Galéra

\section{To cite this version:}

Christine Opagiste, Rose-Marie Galéra. Crystal structure and physical properties of the new ternary compounds Nd3Pt23Si11 and Pr3Pt23Si11. Journal of Alloys and Compounds, 2012, 541, pp.403-406. 10.1016/j.jallcom.2012.06.137 . hal-00725269

\section{HAL Id: hal-00725269 \\ https://hal.science/hal-00725269}

Submitted on 24 Aug 2012

HAL is a multi-disciplinary open access archive for the deposit and dissemination of scientific research documents, whether they are published or not. The documents may come from teaching and research institutions in France or abroad, or from public or private research centers.
L'archive ouverte pluridisciplinaire HAL, est destinée au dépôt et à la diffusion de documents scientifiques de niveau recherche, publiés ou non, émanant des établissements d'enseignement et de recherche français ou étrangers, des laboratoires publics ou privés. 


\title{
Crystal structure and physical properties of the new ternary compounds $\mathrm{Nd}_{3} \mathrm{Pt}_{23} \mathrm{Si}_{11}$ and $\mathrm{Pr}_{3} \mathrm{Pt}_{23} \mathrm{Si}_{11}$
}

\author{
C. Opagiste*, R.-M. Galéra \\ Institut Néel, CNRS-UJF, BP 166, F-38042 Grenoble Cedex 9, France
}

* Corresponding author : Email address: christine.opagiste@grenoble.cnrs.fr (C. Opagiste)

\begin{abstract}
The two ternary compounds, $\mathrm{Pr}_{3} \mathrm{Pt}_{23} \mathrm{Si}_{11}$ and $\mathrm{Nd}_{3} \mathrm{Pt}_{23} \mathrm{Si}_{11}$ have been synthesized for the first time. They both crystallize in the same Fm-3m cubic space group as $\mathrm{Ce}_{3} \mathrm{Pt}_{23} \mathrm{Si}_{11}$. Their lattice parameters are $\mathrm{a}_{\mathrm{Pr}}=16.8633(3) \AA$ and $\mathrm{a}_{\mathrm{Nd}}=16.8498(4) \AA$ for $\mathrm{Pr}_{3} \mathrm{Pt}_{23} \mathrm{Si}_{11}$ and $\mathrm{Nd}_{3} \mathrm{Pt}_{23} \mathrm{Si}_{11}$, respectively. From magnetic and heat capacity measurements, $\mathrm{Nd}_{3} \mathrm{Pt}_{23} \mathrm{Si}_{11}$ is found to present a magnetic transition at $1.6 \mathrm{~K}$, whereas for $\operatorname{Pr}_{3} \mathrm{Pt}_{23} \mathrm{Si}_{11}$, the magnetic susceptibility shows typical paramagnetic Van Vleck behavior at low temperatures.
\end{abstract}

Keywords: Rare earth compounds, Crystal structure determination, Magnetic properties, Heat capacity.

\section{Introduction}

The ternary system RE-Pt-Si (where RE is a rare earth element) has triggered a lot of interest in the last decade because some of its compounds present interesting physical properties such as unconventional superconducting properties, heavy-fermion states or magnetic ordering. The best known compound in this system is $\mathrm{CePt}_{3} \mathrm{Si}$ [1]. Very recent studies of the novel $\mathrm{RE}_{3} \mathrm{Pt}_{23} \mathrm{Si}_{11}$ series have shown that the ferromagnetic $\mathrm{Ce}_{3} \mathrm{Pt}_{23} \mathrm{Si}_{11}$ compound $\left(\mathrm{T}_{\mathrm{C}}=440 \mathrm{mK}\right)$ presents unusual magnetic behavior $[2,3]$ and that some features in $\mathrm{Yb}_{3} \mathrm{Pt}_{23} \mathrm{Si}_{11}$ suggest an unstable character of the $\mathrm{Yb} 4 f$ shell [4]. As part of our studies on this ternary $\operatorname{Re}_{3} \mathrm{Pt}_{23} \mathrm{Si}_{11}$ series, we have successfully synthesized two novel compounds: $\operatorname{Pr}_{3} \mathrm{Pt}_{23} \mathrm{Si}_{11}$ and $\mathrm{Nd}_{3} \mathrm{Pt}_{23} \mathrm{Si}_{11}$. In this paper, we present a study of the structural and physical properties performed on polycrystalline samples of $\operatorname{Pr}_{3} \mathrm{Pt}_{23} \mathrm{Si}_{11}$ and $\mathrm{Nd}_{3} \mathrm{Pt}_{23} \mathrm{Si}_{11}$. These properties are compared to those of $\mathrm{Ce}_{3} \mathrm{Pt}_{23} \mathrm{Si}_{11}$ and to the non-magnetic isomorphous compound $\mathrm{La}_{3} \mathrm{Pt}_{23} \mathrm{Si}_{11}$. 


\section{Sample development and experimental details}

High quality polycrystalline samples of $\operatorname{Pr}_{3} \mathrm{Pt}_{23} \mathrm{Si}_{11}$ and $\mathrm{Nd}_{3} \mathrm{Pt}_{23} \mathrm{Si}_{11}$ have been prepared in an induction furnace. Stoichiometric proportions of the different constituents: Pr or $\mathrm{Nd}(99.9 \%$, Johnson Matthey), Pt (99.95\%, Alfa Aesar) and Si (99.9999\%, Alfa Aesar), were melted in a cold copper crucible under a high purity argon atmosphere. The samples were melted several times to improve the homogeneity. Mass losses during this first step were less than $0.1 \%$. Sample structure and quality were checked by conventional X-ray powder diffraction $(\mathrm{Cu}-\mathrm{K} \alpha$ radiation on a Philipps PW1730 diffractometer).

In the temperature range 1.8 - $300 \mathrm{~K}$, magnetization measurements were performed using two magnetometers based on the extraction method: a commercial Quantum Design MPMS magnetometer and a in-house experimental setup allowing measurements in fields of up to 10.5 $\mathrm{T}$. In the temperature range $0.38-300 \mathrm{~K}$, the heat capacity was measured using the relaxation method on a Quantum Design-Physical Property Measurement System (QD-PPMS).

\section{Determination of the Crystal structure}

Figure 1 shows the powder diffraction patterns collected for $\operatorname{Pr}_{3} \mathrm{Pt}_{23} \mathrm{Si}_{11}$ and $\mathrm{Nd}_{3} \mathrm{Pt}_{23} \mathrm{Si}_{11}$, together with the Rietveld refinements carried out using the FullProf program [5]. For both compounds, the results are consistent with the face-centered cubic structure (Fm-3m space group) already reported for $\mathrm{La}-\mathrm{Ce}$ - and $\mathrm{Yb}_{3} \mathrm{Pt}_{23} \mathrm{Si}_{11}[6,3,4]$. Details of the crystallographic analyses are presented in tables 1, 2 and 3. $\mathrm{Pr}^{3+}$ and $\mathrm{Nd}^{3+}$ ions are located on the $24 d$ sites. The values of these refined lattice parameters are 16.8633(3) $\AA$ and 16.8498(4) $\AA$ for $\operatorname{Pr}_{3} \mathrm{Pt}_{23} \mathrm{Si}_{11}$ and $\mathrm{Nd}_{3} \mathrm{Pt}_{23} \mathrm{Si}_{11}$, respectively. As seen in figure 2, these lattice parameters, supplemented by other known compounds of the series, show behavior consistent with the volume contraction in the lanthanide series. Nevertheless, like in many lanthanide compounds, this behavior is not a smooth linear variation. 


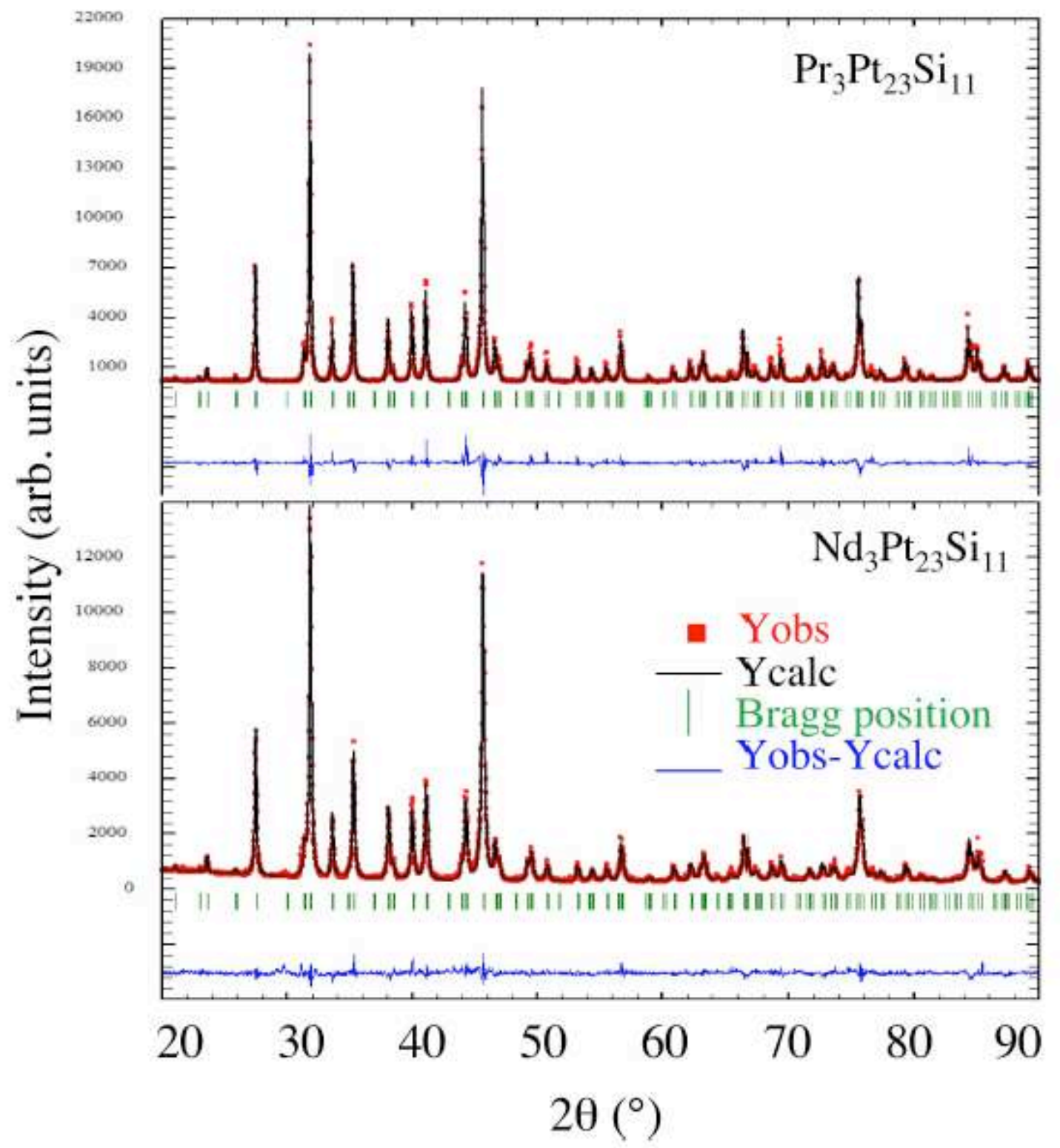

Figure 1: $\mathrm{X}$-ray powder diffraction patterns collected for $\operatorname{Pr}_{3} \mathrm{Pt}_{23} \mathrm{Si}_{11}$ and $\mathrm{Nd}_{3} \mathrm{Pt}_{23} \mathrm{Si}_{11}$. The $\mathrm{X}$-ray wavelengths are $\lambda \mathrm{CuK \alpha _{1 }}=1.54051 \AA$ and $\lambda \mathrm{CuK \alpha _{2 }}=1.54433 \AA$. Full squares represent the observed intensities while the solid lines represent the best fit calculated from a Rietveld refinement. The vertical bars show the ideal Bragg positions while the bottom curves shows the difference between the observed and the calculated intensities. 
Table 1: Crystallographic details.

\begin{tabular}{lll}
\hline Formula from refinements & $\mathrm{Pr}_{3} \mathrm{Pt}_{23} \mathrm{Si}_{11}$ & $\mathrm{Nd}_{3} \mathrm{Pt}_{23} \mathrm{Si}_{11}$ \\
Space group & $\mathrm{Fm}-3 \mathrm{~m}(\mathrm{No} 225)$ & $\mathrm{Fm}-3 \mathrm{~m}(\mathrm{No} 225)$ \\
Structure type & $\mathrm{Ce}_{3} \mathrm{Pt}_{23} \mathrm{Si}_{11}$ & $\mathrm{Ce}_{3} \mathrm{Pt}_{23} \mathrm{Si}_{11}$ \\
$\mathrm{Z}$ & 8 & 8 \\
Lattice constant $(\AA)$ & $16.8633(3)$ & $16.8498(4)$ \\
Cell volume $\left(\AA^{3}\right)$ & $4795.4(2)$ & $4783.9(2)$ \\
Deal $\left(\mathrm{g} / \mathrm{cm}^{3}\right)$ & 14.46 & 14.52 \\
Reflection measured & 284 & 272 \\
Number of refined parameters & 30 & 30 \\
$\chi^{2}$ & 4.58 & 7.96 \\
\hline
\end{tabular}

Table 2: Atomic coordinates and isotropic displacement parameters for $\operatorname{Pr}_{3} \mathrm{Pt}_{23} \mathrm{Si}_{11}$.

\begin{tabular}{lllllll}
\hline Atom & Wyckoff position & $\mathrm{x} / \mathrm{a}$ & $\mathrm{y} / \mathrm{b}$ & $\mathrm{z} / \mathrm{c}$ & $\mathrm{U}$ iso $\left(\AA^{2}\right)$ & Occupation \\
\hline $\mathrm{Pr}$ & $24 d$ & 0 & $1 / 4$ & $1 / 4$ & 1.3 & 1 \\
$\mathrm{Pt}{ }_{1}$ & $32 f$ & $0.0830(1)$ & $0.0830(1)$ & $0.0830(1)$ & 1.2 & 1 \\
$\mathrm{Pt}_{2}$ & $32 f$ & $0.3089(1)$ & $0.3089(1)$ & $0.3089(1)$ & 1.1 & 1 \\
$\mathrm{Pt}_{3}$ & $24 e$ & $0.3741(2)$ & 0 & 0 & 0.8 & 1 \\
$\mathrm{Pt}_{4}$ & $96 k$ & $0.0843(1)$ & $0.0834(1)$ & $0.2523(1)$ & 1.2 & 1 \\
$\mathrm{Si}_{1}$ & $24 e$ & $0.176(1)$ & 0 & 0 & 1.7 & 1 \\
$\mathrm{Si} 2$ & $32 f$ & $0.1682(6)$ & $0.1682(6)$ & $0.1682(6)$ & 1.7 & 1 \\
$\mathrm{Si} 3$ & $32 f$ & $0.3929(6)$ & $0.3929(6)$ & $0.3929(6)$ & 1.7 & 1 \\
\hline
\end{tabular}


Table 3: Atomic coordinates and isotropic displacement parameters for $\mathrm{Nd}_{3} \mathrm{Pt}_{23} \mathrm{Si}_{11}$.

\begin{tabular}{lllllll}
\hline Atom & Wyckoff position & $\mathrm{x} / \mathrm{a}$ & $\mathrm{y} / \mathrm{b}$ & $\mathrm{z} / \mathrm{c}$ & Uiso $\left(\AA^{2}\right)$ & Occupation \\
\hline $\mathrm{Nd}$ & $24 d$ & 0 & $1 / 4$ & $1 / 4$ & 1.0 & 1 \\
$\mathrm{Pt1}$ & $32 f$ & $0.0830(2)$ & $0.0830(2)$ & $0.0830(2)$ & 1.2 & 1 \\
$\mathrm{Pt} 2$ & $32 f$ & $0.3079(1)$ & $0.3079(1)$ & $0.3079(1)$ & 1.3 & 1 \\
$\mathrm{Pt3}$ & $24 e$ & $0.3744(3)$ & 0 & 0 & 0.9 & 1 \\
$\mathrm{Pt} 4$ & $96 k$ & $0.0839(1)$ & $0.0839(1)$ & $0.2504(2)$ & 1.7 & 1 \\
$\mathrm{Si} 1$ & $24 e$ & $0.1789(9)$ & 0 & 0 & 1.6 & 1 \\
$\mathrm{Si} 2$ & $32 f$ & $0.1676(9)$ & $0.1676(9)$ & $0.1676(9)$ & 1.6 & 1 \\
$\mathrm{Si3}$ & $32 f$ & $0.3878(9)$ & $0.3878(9)$ & $0.3878(9)$ & 1.6 & 1 \\
\hline
\end{tabular}

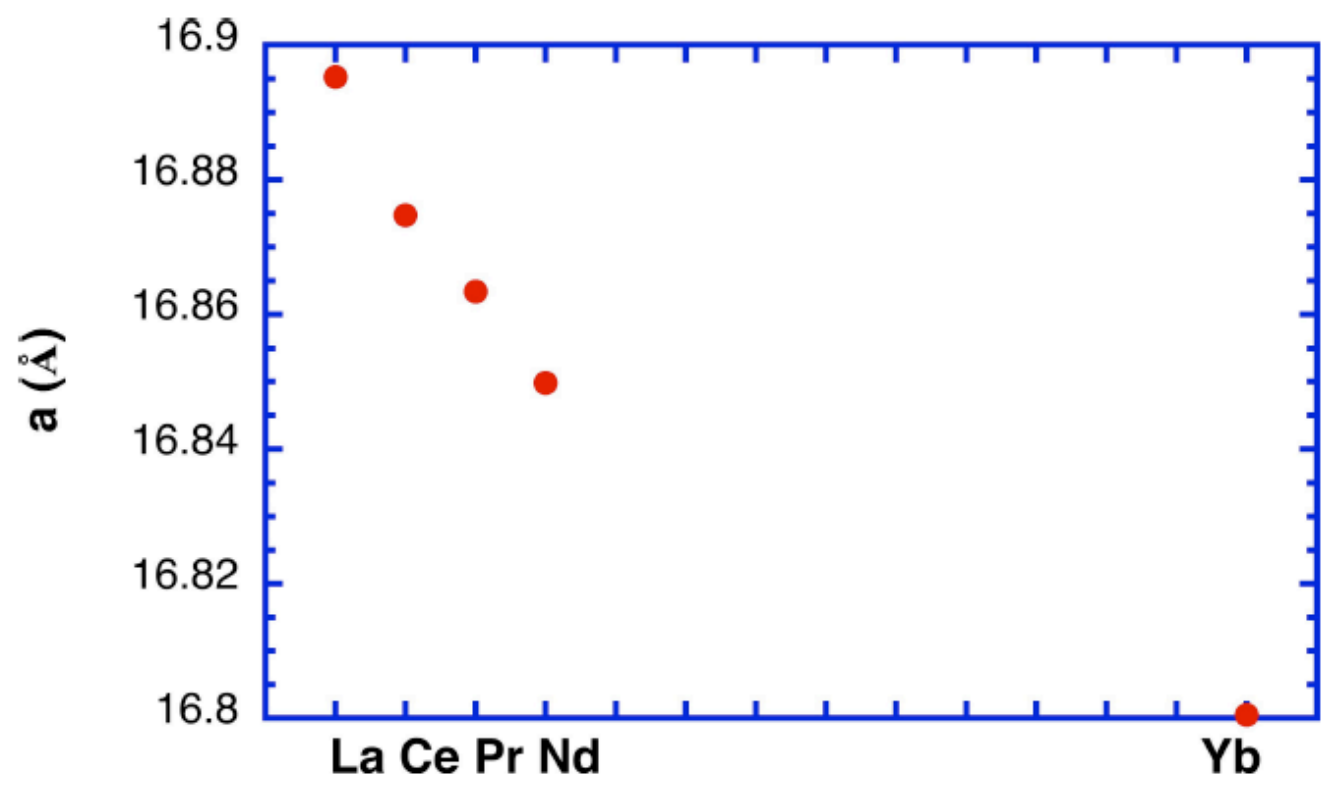

Figure 2: Lattice parameter variation in the $\mathrm{RE}_{3} \mathrm{Pt}_{23} \mathrm{Si}_{11}$ series. The $\mathrm{Yb}$ data comes from reference [4]. 


\section{Magnetic properties}

\section{1. $\operatorname{Pr}_{3} \mathrm{Pt}_{23} \mathrm{Si}_{11}$}

Figure 3 shows the thermal variation of the inverse of the magnetic susceptibility of $\operatorname{Pr}_{3} \operatorname{Pt}_{23} \operatorname{Si}_{11}$. Dots represent the inverse susceptibility deduced from the thermal variation of the magnetization under an applied field of $0.1 \mathrm{~T}, \chi=\mathrm{M} / \mathrm{H}$. At low temperatures, the open diamonds represent the inverse susceptibility obtained from the Arrott plots, $\mathrm{M}^{2}=f(\mathrm{H} / \mathrm{M})$ or $\mathrm{M} / \mathrm{H}=f\left(\mathrm{H}^{2}\right)$. The magnetization curves shown in the inset of figure 3 , show that down to $1.8 \mathrm{~K}$, the magnetization varies linearly with the field and that under an applied field of $5 \mathrm{~T}$, its value is far lower than the $3.2 \mu_{\mathrm{B}}$ expected for the saturated magnetic moment of the $\operatorname{Pr}^{3+}$ ion. This is in agreement with the paramagnetic behavior of the $\operatorname{Pr}^{3+}$ ions. In the temperature range 50-300 $\mathrm{K}, 1 / \chi$ varies linearly with the temperature, consistent with the Curie-Weiss law. From the linear fit of the experimental data, one deduces an effective moment of $3.55 \mu_{\mathrm{B}}$ per Pr ion, in good agreement with the theoretical value, $\mu_{\mathrm{eff}}=3.58 \mu_{\mathrm{B}}$. The solid line in Fig. 3 has been calculated using the CurieWeiss law: $1 / \chi=\mathrm{T} / C-n$, where $\mathrm{C}$ is the theoretical Curie constant for a $\operatorname{Pr}^{3+}$ ion, $\mathrm{C}=2.865 \mu_{\mathrm{B}}$ $\mathrm{K} / \mathrm{T}\left(\mu_{\mathrm{eff}}=3.58 \mu_{\mathrm{B}}\right)$ and $n$ is the molecular field coefficient. The experimental data are well reproduced for $n=-4.8 \mathrm{~T} / \mu_{\mathrm{B}}$. A negative value of $n$ suggests antiferromagnetic exchange interactions. We note however, that at the highest temperatures, the experimental data tends to slightly deviate from the Curie-Weiss line. Below $50 \mathrm{~K}, 1 / \chi$ deviates from the Curie-Weiss law and tends to a constant value $1 / \chi(\mathrm{T}=0 \mathrm{~K})$ of $11.81 \mathrm{~T} / \mu_{\mathrm{B}}$ per Pr. This Van Vleck-type behavior is a direct consequence of the crystal electric field (CEF) effects that can select a non-magnetic ground state for a non-Kramers trivalent ion located in a site of cubic symmetry. In the present case, one would expect either a singlet $(\Gamma 1)$ or a triplet $(\Gamma 3)$ non-magnetic ground state [7]. 


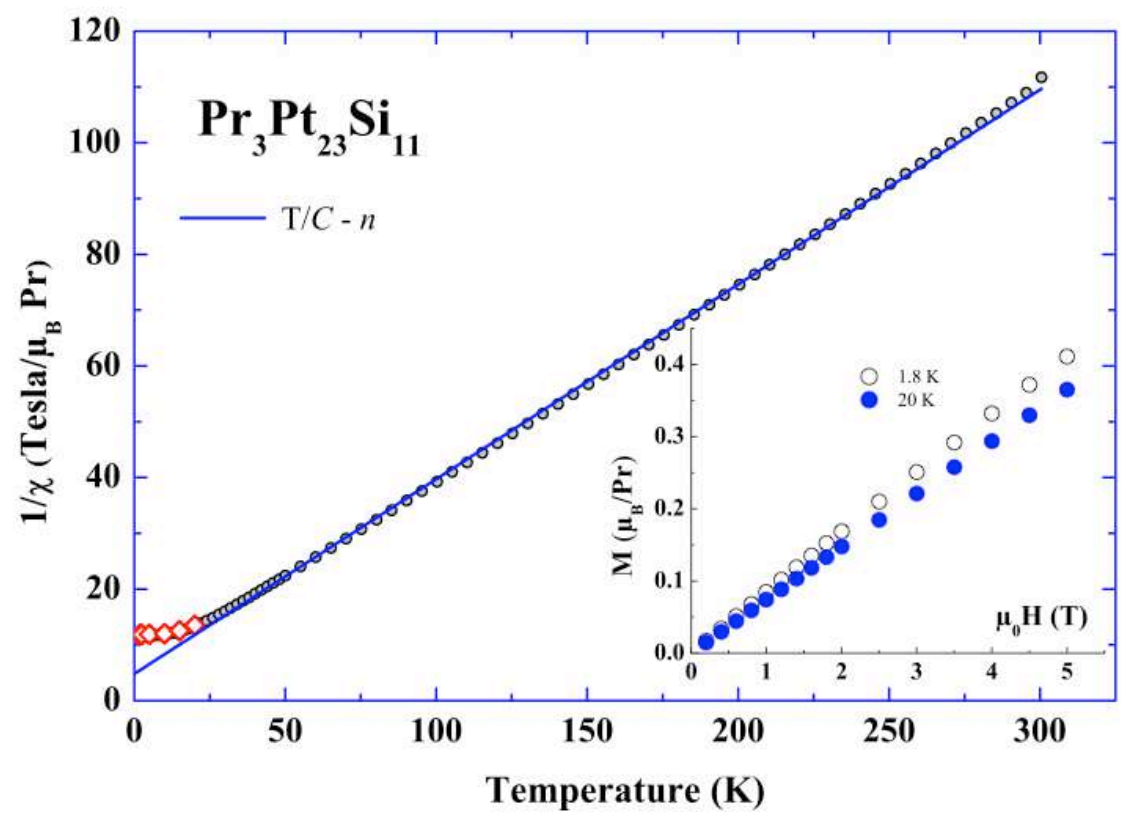

Figure 3: Thermal variation of the inverse magnetic susceptibility of $\operatorname{Pr}_{3} \operatorname{Pt}_{23} \mathrm{Si}_{11}$ : open dots are deduced from the thermal variation of the magnetization under an applied field of $0.1 \mathrm{~T}$ while the open diamonds are from the Arrott plots. The line shows the calculated Curie-Weiss law: $1 / \chi=$

$\mathrm{T} / \mathrm{C}-\mathrm{n}$, with $\mathrm{C}=2.865 \mu_{\mathrm{B}} \mathrm{K} / \mathrm{T}$ and $\mathrm{n}=-4.8 \mathrm{~T} / \mu_{\mathrm{B}}$. The inset shows the field dependent magnetization curves obtained at 1.8 and $20 \mathrm{~K}$.

\section{2. $\mathrm{Nd}_{3} \mathrm{Pt}_{23} \mathrm{Si}_{11}$}

Figure 4 shows the thermal variation of the inverse magnetic susceptibility of $\mathrm{Nd}_{3} \mathrm{Pt}_{23} \mathrm{Si}_{11}$ deduced from Arrott plots. The magnetization curves shown in the inset of figure 4 confirm that $\mathrm{Nd}_{3} \mathrm{Pt}_{23} \mathrm{Si}_{11}$ remains paramagnetic down to the lowest attainable temperature, $1.8 \mathrm{~K}$. However, in contrast to $\operatorname{Pr}_{3} \mathrm{Pt}_{23} \mathrm{Si}_{11}$, the magnetization of the $\mathrm{Nd}$ compound tends to saturate. Under an applied field of $8 \mathrm{~T}$, the magnetization tends to $\approx 1.45 \mu_{\mathrm{B}}$ per $\mathrm{Nd}$ ion.

The thermal variation of the inverse susceptibility presents strong similarities with that of the $\operatorname{Pr}$ compound. $1 / \chi$ varies linearly with temperature down to approximately $25 \mathrm{~K}$, where it shows a downward curvature. A linear fit of the experimental data yields an effective moment of $3.53 \mu_{\mathrm{B}}$ per $\mathrm{Nd}$ ion, slightly smaller than the theoretical value $\mu_{\text {eff }}=3.62 \mu_{\mathrm{B}}$, but nevertheless, in agreement with trivalent $\mathrm{Nd}$ ions. The line in Fig. 4 shows the calculated Curie-Weiss law using the theoretical Curie constant, $\mathrm{C}=2.93 \mu_{\mathrm{B}} \mathrm{K} / \mathrm{T}$ and a value of $\approx-4.8 \mathrm{~T} / \mu_{\mathrm{B}}$ for the molecular field coefficient. At high temperatures, the experimental data deviate clearly from the calculated 
Curie-Weiss line. In diluted rare earth systems, the paramagnetic signal is very weak at high temperatures and may become the same order of magnitude as the magnetic signal of the matrix. This signal, which results from several contributions such as the Pauli paramagnetism of conduction electrons, the Landau diamagnetism of these electrons and the magnetic signal of the allied atoms, can be well accounted for by the signal of the isomorphous La compound. In the present series, the $\mathrm{La}_{3} \mathrm{Pt}_{23} \mathrm{Si}_{11}$ compound has been found to be diamagnetic [3]. This may explain the reduction of the experimental susceptibility with respect to the Curie-Weiss law.

Below $25 \mathrm{~K}, 1 / \chi$ presents a downward curvature and tends to zero as $\mathrm{T}$ tends to $0 \mathrm{~K}$. As for $\operatorname{Pr}_{3} \mathrm{Pt}_{23} \mathrm{Si}_{11}$, this deviation from the Curie-Weiss law of $1 / \chi$ is ascribed to CEF effects. This is also confirmed by the value at which the magnetization saturates; $1.45 \mu_{\mathrm{B}}$ instead of $3.27 \mu_{\mathrm{B}}$ expected for the ${ }^{4} \mathrm{I}_{9 / 2}$ ground state multiplet. As $\mathrm{Nd}^{3+}$ is a Kramers ion, the CEF levels are always magnetic.

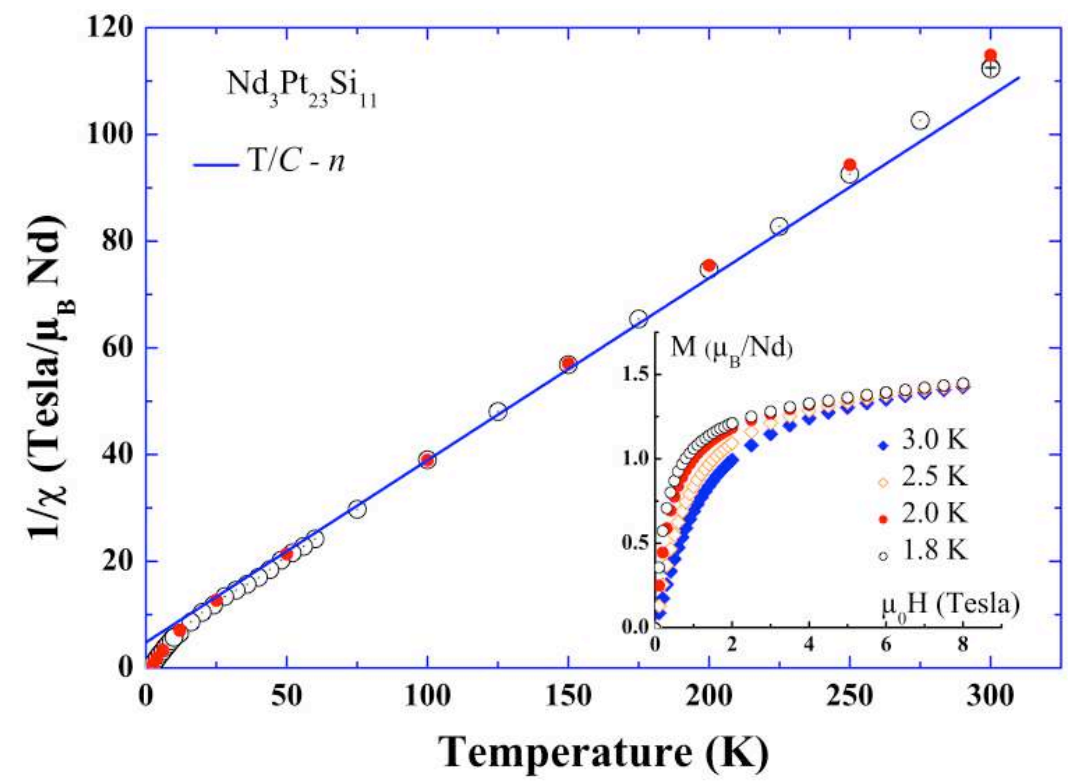

Figure 4: Thermal variation of the inverse magnetic susceptibility of $\mathrm{Nd}_{3} \mathrm{Pt}_{23} \mathrm{Si}_{11}$. The experimental data have all been deduced from Arrott plots: open dots come from the measurements performed with the in-house experimental setup and the full dots from the measurements in the Quantum Design MPMS. The line shows the calculated Curie-Weiss law: $1 / \chi=\mathrm{T} / \mathrm{C}-\mathrm{n}$, with $\mathrm{C}=2.93 \mu_{\mathrm{B}} \mathrm{K} / \mathrm{T}$ and $\mathrm{n}=-4.8 \mathrm{~T} / \mu_{\mathrm{B}}$. The field dependent magnetization curves between 1.8 and $3 \mathrm{~K}$ are shown in the inset. 


\section{Heat capacity}

In figure 5, the specific heat curves of the $\operatorname{Pr}_{3} \mathrm{Pt}_{23} \mathrm{Si}_{11}, \mathrm{Nd}_{3} \mathrm{Pt}_{23} \mathrm{Si}_{11}$ and $\mathrm{La}_{3} \mathrm{Pt}_{23} \mathrm{Si}_{11}$ compounds are compared in temperature range $0.37-30 \mathrm{~K}$. For the $\operatorname{Pr}$ compound, the specific heat measurements show that no transition exists down to $0.37 \mathrm{~K}$. For the $\mathrm{Nd}$ compound on the other hand, the specific heat shows a lambda anomaly at $1.6 \mathrm{~K}$. According to the magnetization curves, this most likely corresponds to a magnetic transition. To determine the nature of this transition, magnetization measurements below $1.6 \mathrm{~K}$ are required. In the inset of Fig. 5, the logarithmic scale emphasizes the broadness of the lambda anomaly at the transition. A non-negligible signal extends up to $3 \mathrm{~K}$. Such a feature can be ascribed to short-range magnetic correlations that may develop well above the temperature at which the long-range magnetic order stabilizes. Magnetic results have shown that the CEF effects are important in $\operatorname{Pr}_{3} \mathrm{Pt}_{23} \mathrm{Si}_{11}$ and $\mathrm{Nd}_{3} \mathrm{Pt}_{23} \mathrm{Si}_{11}$. A tentative determination of the entropy from the experimental specific heat at the transition yields a value very close to $3 \mathrm{R} \ln 2$ for $\mathrm{Nd}_{3} \mathrm{Pt}_{23} \mathrm{Si}_{11}$ (see figure 6). Such a result is in fair agreement with a magnetic doublet (Г6) CEF ground state [7]. Actually, the value of $3 R \ln 2$ is only reached around $4 \mathrm{~K}$, this correlates with the broadness of the lambda anomaly (see Fig. 5) and is consistent with the existence of short-range correlations. Fig. 6 also shows that the entropy of $\operatorname{Pr}_{3} \mathrm{Pt}_{23} \mathrm{Si}_{11}$ remains negligible up to 5-6 K. This is consistent with a singlet $\Gamma_{1} \mathrm{CEF}$ ground state in this compound. At higher temperatures, it is very probable that the excess of specific heat for the $\mathrm{Pr}$ and $\mathrm{Nd}$ compounds, compared to the La compound, is due to the CEF Schottky contribution. 


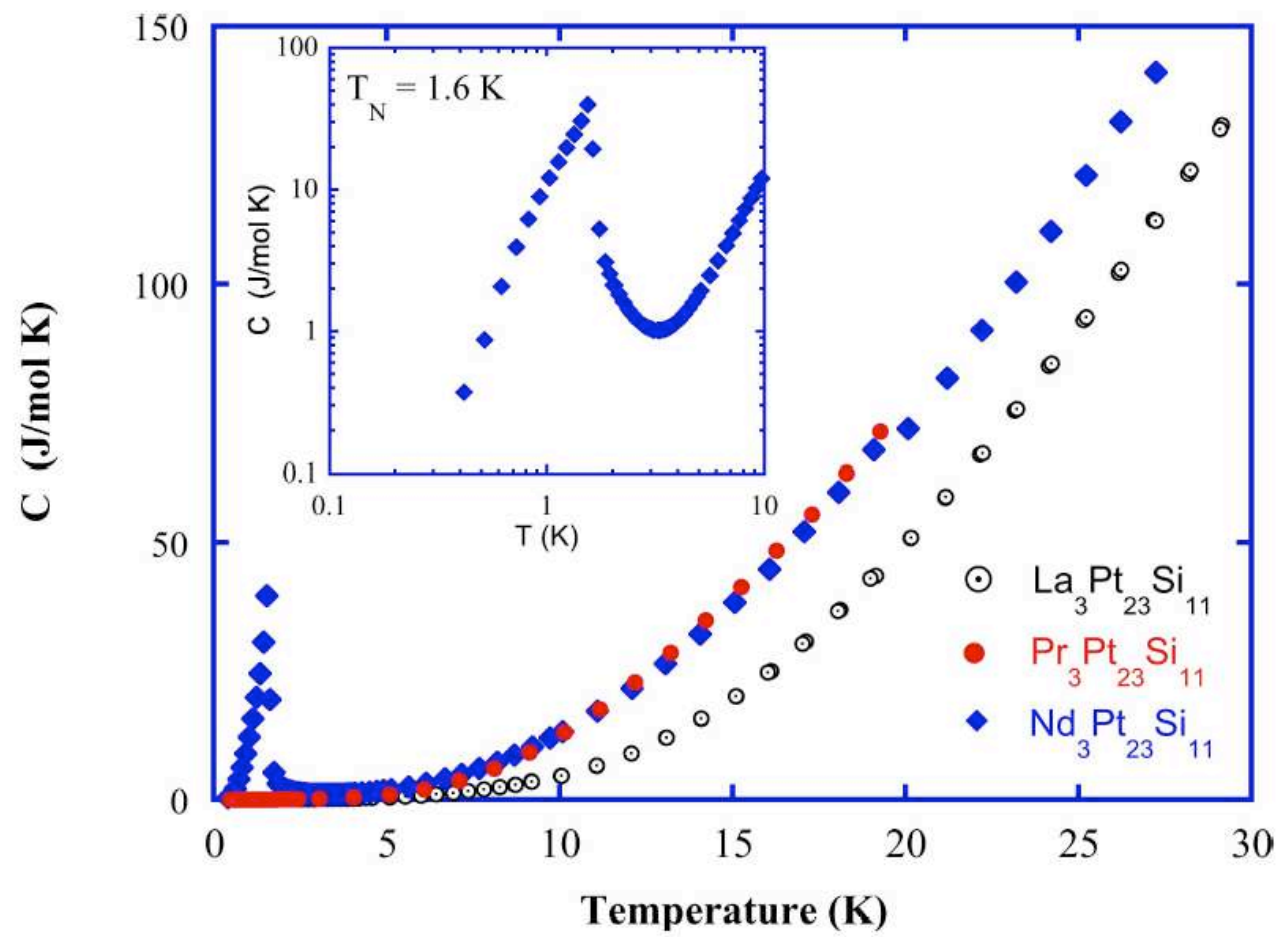

Figure 5: Comparison of the specific heat curves of $\operatorname{Pr}_{3} \mathrm{Pt}_{23} \mathrm{Si}_{11}, \mathrm{Nd}_{3} \mathrm{Pt}_{23} \mathrm{Si}_{11}$ and the nonmagnetic isomorphous compound $\mathrm{La}_{3} \mathrm{Pt}_{23} \mathrm{Si}_{11}$. The inset shows the magnetic transition of $\mathrm{Nd}_{3} \mathrm{Pt}_{23} \mathrm{Si}_{11}$ at $1.6 \mathrm{~K}$ (logarithmic scales).

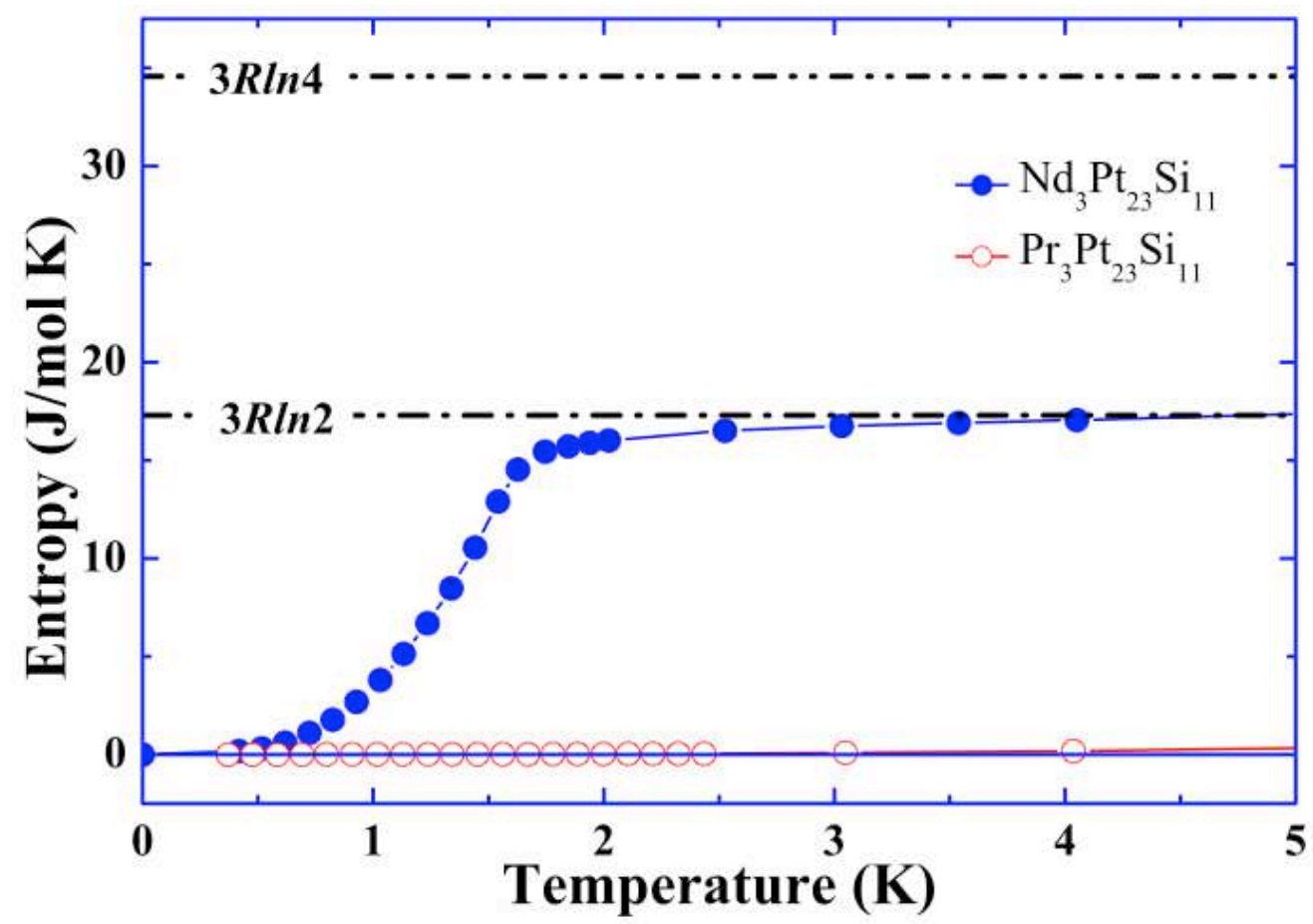

Figure 6: Thermal variation of the entropy per mole for $\operatorname{Pr}_{3} \mathrm{Pt}_{23} \mathrm{Si}_{11}$ (open dots) and $\mathrm{Nd}_{3} \mathrm{Pt}_{23} \mathrm{Si}_{11}$ (solid dots). 


\section{Conclusion}

The two ternary compounds, $\operatorname{Pr}_{3} \mathrm{Pt}_{23} \mathrm{Si}_{11}$ and $\mathrm{Nd}_{3} \mathrm{Pt}_{23} \mathrm{Si}_{11}$, have been synthesized for the first time. The crystallographic studies have confirmed that both compounds crystallize in the same Fm-3m cubic space group as $\mathrm{Ce}_{3} \mathrm{Pt}_{23} \mathrm{Si}_{11}, \mathrm{La}_{3} \mathrm{Pt}_{23} \mathrm{Si}_{11}$ and $\mathrm{Yb}_{3} \mathrm{Pt}_{23} \mathrm{Si}_{11}$. In this series, one observes a reduction of the lattice parameter with the increase of the rare earth atomic number, in agreement with the contraction of the lanthanides. Magnetic and heat capacity measurements reveal that the crystal electric field effects are important in the $\mathrm{Pr}$ and $\mathrm{Nd}$ compounds. For instance in $\operatorname{Pr}_{3} \mathrm{Pt}_{23} \mathrm{Si}_{11}$, the CEF selects a non magnetic ground state leading to a Van Vleck paramagnetic behavior at low temperatures, while in $\mathrm{Nd}_{3} \mathrm{Pt}_{23} \mathrm{Si}_{11}$, it strongly reduces the value of the magnetic moment. For this last compound a transition, ferromagnetic or antiferromagnetic, is observed at $1.6 \mathrm{~K}$ in the specific heat data.

\section{Acknowledgments}

We greatly acknowledge the technical assistance of A. Hadj-Azzem, J. Balay, D. Dufeu, E. Eyraud and P. Lachkar from the Néel Institute.

\section{References}

[1] E. Bauer, H. Kaldarar, A. Prokofiev, E. Royanian, A. Amato, J. Sereni, W. Bramer-Escamilla, I. Bonalde, J. Phys. Soc. Jpn. 76 (5) (2007) 051009.

[2] C. Opagiste, C. Paulsen, E. Lhotel, P. Rodiere, R.-M. Galera, P. Bordet, P. Lejay, J. Magn. Magn. Mater. 321 (6) (2009) 613 - 618.

[3] C. Opagiste, R.-M. Galéra, M. Amara, C. Paulsen, S. Rols, B. Ouladdiaf, Phys. Rev. B 84 (13) (2011) 134401.

[4] D. Kaczorowski, A. Gribanov, S. Safronov, P. Rog1, Y. Seropegin, J. Alloys Compd. 509 (37) (2011) 8987-8990.

[5] J. Rodriguez-Carvajal, Satellite Meeting on Powder Diffraction of the XV Congress of the IUCr, Book of Abstracts, Toulouse, France, 1990, p. 127.

[6] A. I. Tursina, A. V. Gribanov, Y. D. Seropegin, K. V. Kuyukov, O. I. Bodak, J. Alloys Compd. 347 (1-2) (2002) 121 - 123.

[7] K. Lea, M. Leask, W. Wolf, J. Phys. Chem. Solids 23 (10) (1962) 1381 - 1405. 